\title{
KATNISS AS A REPRESENTATION OF GIRL POWER IN HUNGER GAMES TRILOGY
}

\author{
Toisuta, E.G. ${ }^{1}$ and Handojo, P.F. ${ }^{2}$ \\ 1,2 English for Creative Industry, Faculty of Letters, Petra Christian University, Siwalankerto 121-131, \\ Surabaya 60236, East Java, INDONESIA \\ Emails: m11413058@john..petra.ac.id; priskafebrinia@petra.ac.id
}

\begin{abstract}
This study is about the representation of girl power in Hunger Games trilogy.Hunger Games trilogy shows how women that are represented by the main character "Katniss", can do what they want regardless others people opinion. It shows that Katniss as the main character lives in a society that does not have roles between man and woman by showing some action through her characterisctics in the story that against the culture and society. She is able to do anything without thinking about what man or woman should do. Thus, this thesis aims at showing girl power characteristics that are being represented by Katniss. Therefore, I will analyze girl power characteristics in Katniss by using girl power concept. Moreover through this analysis, I find that there are some girl power characteristics that are being represented by Katniss. First, she is an independent woman. Second, she is equally depends on her "brains and brawn". Third, Katniss is a self-determined woman. For the result of the analysis, it can be concluded that Katniss is the representation of girl power that is shown through her action, words, and thoughts.
\end{abstract}

Key words: Katniss, feminism, girl power, representation

\section{INTRODUCTION}

Hunger Games is considered as a dystopian fiction because of the element of the dystopian story, which is a war between the government and the people that are flow within the story in the book. Moreover, Katniss as the protagonist character, who fight to the death against other people (tributes) in the arena due to the life or death game that was created by the government in order to control the society.

Steven (2014) said that the Hunger Games can be compared to high school as a "...cutthroat race for high-school popularity becomes an annual televised fight." Readers may see high school as a dystopian society because of the political stigmas that could possibly exist. (as cited in The Rising Popularity of Dystopian Literature, 2015).

Katniss, the main character is the one that I am going to analyze in this article. At first, Katniss is seen as someone who is powerless but suddenly she becomes a girl with a power and become a heroine. She gives a new hope to other people to rebel against Capitol. Katniss, the Mockingjay or the symbol of the rebellion is portrayed as a strong and independent woman. When she was still in the game, Katniss shows her capabilities as an independent woman that can make her own decision. Katniss is a smart woman. In the game, she is shown as a woman with many plans on how to survive in the game. Every action or decision that she wants to take, she will think of it carefully. Moreover, Katniss is also showing her archery skill in the game. It means that she does not only rely on her brain to think, but also relies on her skills. She uses her archery skill to help her kill other tributes and it becomes her weapon. Katniss's characteristic is portrayed a symbol of the idea of girl power, therefore, every actions that she does, implied the girl power characteristic. She is also shows herself as a self-determined woman. She is determined in oing anuthing that relates to her life. Thus, how Katniss is potrayed as a symbol of girl power in the book and it is interesting to be discussed.

In order to analyze Katniss's characteristic, I will use the theory girl power in the third-wave feminism. However, there is a term that I need to explain first which is "representation". Acccording to Oxford Dictionary, representation means "The description or portrayal of someone or something in a particular way" (ofxorddictionary.com). Katniss as the representation shows to the people that there are some things which is the characteristic of the girl power that she embraces. Thus, representation in here means the way Katniss potrays the characteristic of girl power through her 
actions, words, and thoughts. Furthermore, girl power is a term used for female empowerment in the 90s. "As if girl power appeared as a promise of an all-female world of fun, sassiness, and dressing up to please your (girls and women) self and it is up to you" (Griffin, 2004, p. 33). The first charcteristic of girl power is being independent. Inness (2004) said that the tough woman that shows the girl power characteristic is likely to be independent and does not requiring any supports (p. 13). "Independent means she doesn't allow the culture to define her, because independent woman is empowered to choose her companions, belief system, and standards based on what she deems is right for her" (Johnson, 2013). Women have choices and rights to choose what they want and what they want to do. Being independent women means doing everything within their own will in terms of what they think is right and wrong. They do not allow others to construct their belief and understanding. The second characteristic of girl power is being able to depend equally on "brains and brawn". Iness (2004) stated that "today, tough women have changed from original Angels and other similar figures and can depend equally on brains and brawn." (pp. 14-15). The "brains and brawn" means that woman has a skill that she contributes to the society. Her intelligence makes her competent, able to help others, and not totally dependent on another person for her entire existence. The third characteristic of girl power is self-determination. Bettis and Addams (2005) explained that "women within girl power are daring athletes, not silly beauty queens. They are also independent, fearless and self-determined" (p. 103). Women should not only depend on their beauty but they have something behind more than it. They implied that women can use all of the traits or characteristics that they have in their life to help them. One of the characteristics is by being self-determined. "Selfdetermination itself means to be able to determine for oneself the course of one's own life" (Stalley, 1978). It means that everything that relates to one's life, they are free to choose what should and what should not they do. It also means that one choose what she think is right for her and live accordingly to it. The concept of girl power in woman is already been around for a long time. The figure of strong women such as Lara Croft, Xena, Buffy the Vampire, Alias, Charlies's Angels, and many more are women in action-adventure films that popular media created to follow the term girl power. Therefore, I am going to use this theory to analyze Katniss as a representation of charactersitic of girl power in being independent, depending equally on "brains and brawn", and being selfdetermined woman.

\section{BEING INDEPENDENT}

Being independent is one of the girl power characteristics. Being independent woman itself means "a woman who pays her own bills, buys her own things, and does not allow a man to affect her stability or self-confidence. She supports her self on her own entirely and is proud to be able to do so" (Moody, 2011). It means that as an independent woman, she needs to support her own life and do not let other people interfere with her life. Being able to support herself is something that she should be proud of because she is not depending on anyone and by not depending on other people, she can just be whoever or whatever she wants. First of all is Katniss shows the girl power characteristic in independently believing her own decision. By becoming the Mockingjay, the symbol of the rebelion, there are some consequences that she needs to accept. One of them is that her sister is killed by President Snow because of rebellion towards Capitol. That is a part of her decision making and she needs to take the consequences.

"My name is Katniss Everdeen. I am seventeen years old. My home is District 12. There is no District 12. I am the Mockingjay. I brought down the Capitol. President Snow hates me. He killed my sister. Now I will kill him. And then the Hunger Games will be over...." (Collins, Mockingjay, p. 352)

From the quotation above, Katniss decides to kill President Snow in order to stop the Hunger Games to stop the rebellion and injustice. Through the story, Katniss needs to make many decisions. Every decision that has been made by her are for herself and other people. When making a decision, Katniss shows that she is very persistent in believing her decisions. She never going back when she makes her decision. She believes in it until the end. In her words "I will kill him" shows her independent character in believing that she will kill Snow and she is the one who decides it. She is independently believing in her own choices and she is confident about it.

Second, Katniss shows her independence in making her own decision and fate. Katniss is choosing her own way and showing that she can make her own decision and also in her own fate. It 
can be seen in the first book of Hunger Games, Katniss went to the 73rd Hunger Games, there, she makes many decision in order to survive. One of her decisions is killing other participants. That is the rule for all tributes to do to become a winner.

"That nest may be the sole option I have left. If I can drop it down on them, I may be able to escape. But I'll risk my life in the process." (Collins, Hunger Games, p. 186)

"It's now or never, I think, and begin to saw. Blisters burst on my right hand as I awkwardly drag the knife back and forth. Once I've got a groove, the work requires less effort but is almost more than I can handle. I grit my teeth and saw away occasionally glancing at the sky to register that there were no deaths today. That's all right. The audience will be sated seeing me injured and treed and the pack below me." (Collins, Hunger Games, p. 187).

Katniss shows that she makes her own decision which is to kill other tributes to survive. When she is commited to her decision, she will do anything in order to carry out her decision. In the first quotation, Katniss said "That nest may be the sole option I have left.", it shows that the only option for her to suvive is by using the nest. Thus, she makes decision in sawing the nest that can be seen quotation "It's now or never, I think, and begin to saw.", it is shows her action and independently in making the decision.

Katniss is also showing her independence in deciding her own fate. Katniss as anindependent woman is free to decide anything that relates to her life. Her lifes is her own responsibility thus, Katniss is able to control and choose her own fate. What she should do and be is up to her because she is free to decide it for herself. Katniss independent in deciding her own fate can be seen in the quotation bellow;

"Gale's two little brothers and a sister. Prim. And you may as well throw in our mothers, too, because how would they live without us? Who would fill those mouths that are always asking for more? With both of us hunting daily, there are still nights when game has to be swapped for lard or shoelaces or wool, still nights when we go to bed with our stomachs growling. "I never want to have kids," I say." (Collins, Hunger Games, p.

In here, Katniss decides that she does not want to have kids because it is already hard for her to feed them. It is hard for them also to live and survive in a Hunger Games world. Just like the the meaning of independent according to Oxford Dictionary that independent means "Free from outside control; not subject to another's authority" (oxforddictionary.com). It means she is able to decide anything that relates to her life and she is free to do it. As a woman, Katniss shows that to be able to decide anything that relates to her life. Moreover, when she is able to decide anything in her life, it is shown that she is very independent.

Third, Katniss show herself as an independent woman that does not let people, society, or culture to define her. As an independent woman, Katniss does not let people decide something for her.

"They can design dream weapons that come to life in my hands, but they will never again brainwash me into the necessity of using them. I no longer feel any allegiance to these monsters called human beings, despise being one myself." (Collins, Mockingjay, p. 377)

The quotation above is about how Katniss independently shows that she refuses to be controled. "Independent means she doesn't allow the culture to define her....." (Johnson, 2013). As Johnson said, in the quotation above, Katniss shows that she does not let society, culture or anyone to control or define what should she do. "They" in the quotation above refers to her society which is Panem and anyone that realtes to it. As a woman, she is independent in expressing her voice about controling other people. She shows her action against her society that wants to control her. Moreover, it shows that as an independent woman, sheknows what is right and what is wrong for her so that people cannot control her. In the quotation above, Katniss shows that people can make anything for her to use against the capitol but she does not let them control her. She does not let them choose or decide something for her. As a woman, Katniss is showing that by independently believing in herself, she does not let other people determine her. She has a right to choose and decide for herself.

Fourth, Katniss also independently chooses her companion. Katniss does not let people or even her family in choosing a mate for her. Katniss is an independent woman that shows she can choose or decide anything by herself even her companion. Katniss shows that even to choose a mate, she chooses it by using her own thinking. 
"There's not the least indication that love, or desire, or even compatibility will sway me. I'll just conduct an unfeeling assessment of what my potential mates can offer me. As if in the end, it will be the question of whether a baker or a hunter will extend my longevity the most."

(Collins, Mockingjay, p. 330)

The quotation above shows how Katniss making her own decision in relation to her companions.According to Innes (2004), women are taught to expect man to save them (p. 15). It is the culture that shows what woman should do and also it potrays how the culture says about woman feelings about love. It can be said in other words that woman is taught to wait for man who she loves to save them. Howeverin the quotation "There's not the least indication that love, or desire, or even compatibility will sway me" shows Katniss's perspective against the culture. Katniss shows that she does not want to wait for someone or even thinking about love. She can choose anyone that she wants. Johnson (2013) said that "woman is empowered to choose her companions." As an independent woman, Katniss's prespective about love and desire are something that will not sway her from her own goal. Katniss does not use her feelings to determine her mate because her prespective toward love and mate is different and it can be seen from her action whe she has to choose between Peeta and Gale. She needs someone to become her partner in life not only to fight but to accompany her and it reflects on her saying that "whether a baker or a hunter will extend my longevity the most." Thus, it shows Katniss's perspective about a mate is not about someone she loves or she cannot survive without but it is about someone who will help her to achieve her goal. Her action of choosing her mate above, shows her independent action that even in choosing her own mate she is independently decide for her own self. She does not let people to choose for her but as an independent woman who is free to decide anything, she shows that she is also free to decide her own mate.

Katniss represents one of girl power characteristics which is an independent woman. As an independent woman, Katniss knows what she wants and she does not let other people determine her choices. She shows the girl power characteristics by independently making her own decisions, believing in her own decision, following what she thinks is right, and free to choose her own companion. Katniss shows all of it in her action, words, and thoughts.

\section{DEPENDING EQUALLY ON "BRAINS AND BRAWN"}

According to Oxford Dictionary brains is "Intellectual capacity" and brawn is "Physical strength in contrast to intelligence" (oxforddictionary.com). Depending equally in "brains and brawn" means that as a woman, she does not have to use only her strength to solve the problem but, shealso depends on her knowledge or intelectual. Katniss is one of the women that used her "brains and brawn" to survive. Katniss always depends on her "brains and brawn" when she needs to solve her problem.

Katnis uses her skill (brawn) in surviving. Katniss is known for her archery skill, and she uses her skill wisely. Katniss uses her archery skill to help her family in providing food for them and also in defending herself in the game. Katniss shows that as a woman, she can use her skill to help people. Everyone knows her skill as an archer, as she always hunts in her district for her family.

"But I retrieved the small bow and arrows he'd made me from a hollow tree. I probably didn't go more than twenty yards into the woods that day. Most of the time, I didn't go more than twenty yards into the woods that day. Most of the time, I perched up in the branches of an old oak, hoping for game to come by. Afterseveral hours, I had the good luck to kill a rabbit." (Collins, Hunger Games, p. 50)

Katniss shows that the fact she is the one who hunts for the family and also being able to use bow and arrow to hunt means traditional gender roles is not exist inthe society. There is not any rule in Katniss's society that tells her that woman should be a cooker and man should be thehunter to survive. Thus, Katniss shows that a woman can be whatever she wants and can uses anything to help her survive. According to Brennan about woman's physical strength (2016), "don't let others determine the limits of your aspirations. Understand your assets, skills and unique qualities then find where they can be applied" (as cited in The Woman Of Polo - Beauty, Brains And Brawn). She said that as women, they need to use their skill and apply it to help them and others. In relation to Katniss, she shows that with the skills that she got, she hunts for her family. She uses her skill to help her family in surviving because she understand her family condition in district 12 which is hard to find 
food and they are also poor. Thus, Katniss ability to hunt helps her to find food for her family in district 12. In here, Katniss knows what is she capable of and tries to use it for her own benefit.

Katniss also shows that she is not only good at using her bows but also she is a smart woman. On top of being able to hunt for food and defend herself, she's a strategic player of the games. Katniss is not only depended on her brawn but she is also depending on her brains. She is relying on her quick wit to help her solve problems.

"Yes, they have to have a victor. Without a victor, the whole thing would blow up in the Gamemakers' faces." (Collins, Hunger Games, pp. 344)

"[..... If Peeta and I were both to die, or they thought we were ... My fingers fumble with the pouch on my belt, freeing it. Peeta seesit and his hand clamps on my wrist. "No, I won't let you." "Trust me,” I ～whisper." (Collins, Hunger Games, p. 344)

"[.....] I spread out my fingers, and the dark berries glisten in the sun. I give Peeta's hand one last squeeze as a signal, as a good-bye, and we begin counting. "One." Maybe I'm wrong. "Two." Maybe they don't care if we both die. "Three!" It's too late to change my mind. I lift my hand to my mouth, taking one last look at the world. The berries have just passed my lips when the trumpets begin to blare." (Collins, Hunger Games, p. 345)

From the quotation above, it shows how Katniss does not only depend on her skill as an archer but she also uses her brain in order to help her becoming the winner. Inside the game, Katniss needs to choose who to save and become the winner, herself or Peeta. However, Katniss is smart, she uses her brain to find a solution to save herself and Peeta. She knows that Capitol needs a victor because that is the rule of the game and without a victor the game will be nothing. Thus, she tries to challenge the Capitol by killing themselves by eating the berries so that there will be no victor. In the end, Capitol cannot let that happen and announce both of them as victors. Katniss plan to deceive the Capitol to help her and Peeta. She is braveto use her brain (plan to eat the berries) to challenge Capitol which is powerfulalthough she knows the consequences of it. She already thinks twice before she decides to eat the berries. As a woman, Katniss shows that her knowledge in terms of her quick wit in deciding something is a benefit for her. She uses her knowledge to solve her problems and it helps her. In the end, Katniss shows the characteristic of girl power which is equally depending on her "brain and brawn".

Katniss shows that she can depends equally on her "brains and brawn." She uses both of it to help her and other people and both of it becomes a benefit for her especially inside the game. As a woman, when she depends on her "brains and brawn", the benefit that she can get is more. She gets the benefit when she uses her "brains and brawn." She can help herself, her family, and other people.

\section{SELF-DETERMINED}

Katniss shows the girl power characteristic which is her self-determination. She believes that to reach her goal, she needs to do anything to reach it and commit herself until she makes it. The definition of "Self-Determination" in the Oxford Dictionary is " The process by which a person controls their own life." (ofxorddictionary.com). It means that one is able to control anything in their life without anyone to interfere it. According to Manzanera-Romána and Brändleb (2015) self-determination ina woman is "the main competence is to swallow the fear, saying, 'I will take the step, I'm going to risk, the risk.' (p. 42). When women determined to do something, they need a courage in pursuing their goal and they will risk anything. They need to believe in their decision and do not turn their back on it.

First of all, Katniss shows her self-determined in doing all things that she needs to do to reach her goal. Inside the game, Katniss needs to survive and that is her goal. One of her determination in doing anything to reah her goals inside the game can be seen from her action bellow;

'I'm hungry, too, but I don't dare break into my precious store of crackers and beef yet. Instead, I take my knife and go to work on a pine tree, cutting away the outer bark and scraping off a large handful of the softer inner bark. I slowly chew the stuff as I walk along. After a week of the finest food in the world, it's a little hard to choke down. But I've eaten plenty of pine in my life. I'll adjust quickly." (Collins, Hunger Games, p.

From the quotation above it shows how Katniss is determined to find a food for her to relieve her hunger by eating the pine's bark. "People who are self-determined know what they want and how to get it. They choose andset goals, then work to reach them" ("A National Gateway to Self- 
Determination," n.d.). It means that someone who is with self-determined will do anything to reach their own goals. In relation to Katniss, Katniss sets her own goal to survive inside the game and her action to reach her goal is to eat anything that can help her survive. Katniss is determined to eat the pine in order to reach her goal which is to survive. Even though it is only by eating a pine's bark, she is still determined to eat it and will make herself adjust to eating it. In her word "I'll adjust quickly", shows her determination to eat pine's bark to help her survive. It is shown that Katniss is determined to do anything in order to reach her goal.

In conclusion, Katniss represent girl power characteristic which is self-determined. Katniss shows that as a woman when she has a goal in her life, she needs to do anything to reach it. Moreovr, she is able to determine goals for herself and she is free to determine anything. Bettis and Addams (2005) explained that "women within girl power are daring athletes, not silly beauty queens. They are also independent, fearless and self-determined" (p. 103). She is determind to do anything in order to reach her goal. As a woman, Katniss shows her determination by doing whatever she can in order to survive and nothing can stop her from that.

\section{CONCLUSION}

In this article, I analyze Katniss as the representation of girl power. As the representation of girl power, she shows that girl power is a power that women can have and perform. It is shown in Katniss characteristics which is by her action, words, and thought. The analysis shows that Katniss represents the girl power by being independent, depending equally on her "brains and brawn", and being self-determined. The first characteristics of Katniss that represent the girl power are by being independent. Katniss shows her independence in believing her own decisions. Katniss needs to make a decision regarding herself and other people because she is the Mockingjay. When she makes a decision, she believes in her decision without regrets. Katniss's goal is to kill President Snow and she does not regret her own choices, even though from her decisions there are consequences that she needs to take. As a woman, Katniss shows that she is very persistence and independently believing in what she thinks is right which is her own decision. Katniss also shows that an independent woman does not let people, society, or culture to define her. As a woman, katniss is really independent. She does not let other people control her. In her action, she does thingsand decides on her own. She also shows her independent in making her own decision. Katniss needs to survive inside the game thus, she needs to kill other tributes even though she knows the consequences. She knows that there is a risk but she already commits to her decision, which is to kill other tributes. As an independent woman, Katniss knows what she wants and she does not let other people determine her choices.

The second is depending equally on her "brains and brawn". Depending equally on brains and brawn means she depends equally on her knowledge and physical strength. She shows that as a woman she can equally depend on both of it. First, she uses her "brawn" (skill) in surviving. Katniss is known for her archery skill in the game. She always chooses arrows and bow as her weapons. As an archer, she uses her skill to help her defending her life from other tributes inside the game. She also hunts for her family and it also shows her position in the family as head of the family. It is implied that there is not any gender roles that control them as a man and woman in the society. Katniss also shows that being able to use bow and arrows is normal as a woman. She shows that there is no line that distinguishes man from a woman because she can do anything according to herself. Next, Katniss is a smart woman and relying on her quick wit to help her solve problems. Katniss is not only shown that she is good at using bow and arrows but she is also good at using her "brains". She uses her brain which is her knowledge to help her solving the problem. In the end, she shows that as a woman, she can easily depend on her "brains" and not only to her "brawn".

The last characteristic is self-determined. Self-determined means that shecandetermine anything that relates to her own life.First, Katniss Katniss shows her self-determination in doing all things that she needs to do to reach her goal. She shows that as a self-determined woman, she has will do anything in order to reach her goals. She is willing to do anything to achieve it, even to risk herself.As a woman with self-determination, she has to be ready for all the consequences and risks. That is the responsibility that she needs to take and Katniss shows that self-determination characteristic that she she needs to believe in herself and does not turn her back on it.

In conclusion, the analysis above has proved that Katniss is a representation of the girl power in the Hunger Games trilogy, which are shown in her actions, words, and thoughts. Katniss delivers 
the message of girl power by being independent, depending equally on "brains" and "brawn", and being self-determined. She conveys what is exactlya woman with a girl power that can live in the massive world and survive.

\section{REFERENCES}

A National Gatewayto Self-Determination. (n.d.). What Is Self-Determinationand Why Is It Important? Retrieved January 11, 2017, from http://buildingalife.ku.edu/sites/default/files/Self-Determination_Wehmeyer.pdf.

Bettis, Pamela J., Adams, Natalie G. (2005). Geographies of Girlhood: Identities In-between. Routledge

Collins, Z. (2008). Hunger Games. Singapore: Scholastic Press.

Collins, Z. (2009). Catching Fire. Singapore: Scholastic Press.

Collins, Z. (2010). Mockingjay. Singapore: Scholastic Press.

Griffin, C. (2004). Good girls, bad girls: Anglocentrism and diversity in the constitutionof contemporary girlhood. In A. Harris (Ed.), All about the girl: Culture, powerand identity, (pp. 29-43). New York: Routledge.

Inness, S. (2004). Action Chicks: New Images of Tough Women in Popular Culture. US: Palgrave Macmillan.

Johnson, M. (2013, February 19). Define a Strong, Independent Woman for Yourself and Then Live It. Retrieved September 24, 2016, from https://blackandmarriedwithkids.com/2013/02/define-a-strong-independent-woman-foryourself-and-then-live-it/

Manzanera-Román, S., Brändle, G. (2015, May 15). Abilities and skills as factors explaining thedifferences in women entrepreneurship. Retrieved September 24, 2016, from http://linkinghub.elsevier.com/retrieve/pii/S2215910X16000021?via=sd

Moody, Mia. (2011, April). The meaning of "Independent Woman" in Music. Retrieved September 21, 2016, from https://www.thefreelibrary.com/The+meaning+of+\%22Independent+Woman\%22+in+musi c.-a0258603834

Stalley, R. F. (1978). Self-Determination. BMJ. Journal of Medical Ethics, Vol. 4, No. 1. Retrieved November 3, 2016, from http://www.jstor.org/stable/27715681

The Rising Popularity of Dystopian Literature. (2014, April 20). Retrieved June 10, 2016, from http://the-artifice.com/popularity-of-dystopian-literature/

The Women Of Polo - Beauty, Brains And Brawn. (n.d.) Retrieved November 11, 2016, from http://equestrio.com/insider/the-women-of-polo-beauty-brains-and-brawn/ 